\title{
Soil water response of plant functional groups along an artificial legume grassland succession under semi-arid conditions
}

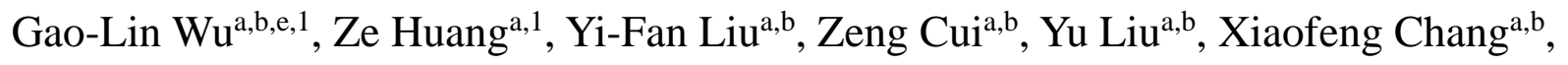 \\ Fu-Ping Tian ${ }^{c}$, Manuel López-Vicente ${ }^{\mathrm{d}}$, Zhi-Hua Shi ${ }^{\mathrm{a}, \mathrm{b}, \mathrm{e}, *}$
}

a State Key Laboratory of Soil Erosion and Dryland Farming on the Loess Plateau, Institute of Soil and Water Conservation of Northwest A \& F University, Yangling, Shaanxi 712100, China

${ }^{b}$ Institute of Soil and Water Conservation, Chinese Academy of Sciences and Ministry of Water Resource, Yangling, Shaanxi 712100, China

${ }^{c}$ Lanzhou Institute of Husbandry and Pharmaceutical Sciences of Chinese Academy of Agricultural Sciences, Lanzhou, Gansu 730050 China

${ }^{d}$ Department of Soil and Water, Experimental Station of Aula Dei, EEAD-CSIC, Zaragoza 50059, Spain

${ }^{e}$ CAS Center for Excellence in Quaternary Science and Global Change, Xi'an, 710061, China

* Corresponding author at: State Key Laboratory of Soil Erosion and Dryland Farming on the Loess Plateau, Institute of Soil and Water Conservation, Chinese Academy of Sciences/Northwest A \& F University, NO. 26 Xinong Road, Yangling, Shaanxi Province 712100, China. E-mail address: shizhihua70@gmail.com (Z.-H. Shi).

${ }^{I}$ These authors contributed equally to this work and are co-first authors.

Received 6 January 2019; Received in revised form 11 July 2019; Accepted 21 July 2019 Available online 26 July 2019: https://www.sciencedirect.com/science/article/pii/S0168192319302783 Published online in Elsevier ScienceDirect: https://doi.org/10.1016/j.agrformet.2019.107670 Agricultural and Forest Meteorology Volume 278, 15 November 2019, 107670

Running Head: Soil water response of plant functional groups.

\begin{abstract}
Drought can cause and accelerate the degradation of planted legume grassland, and the changes in plant community composition can further influence soil physical properties. Here, the soil water response of different plant functional groups (legumes, grass, and forbs) were studied along a legume grassland
\end{abstract}


degradation succession according to the above-ground biomass and the proportion of each functional group. In particular, changes in the soil water storage (SWS), soil properties (soil capillary porosity (CP), and soil organic matter) and plant traits (proportion of functional groups and below-ground biomass) were quantified in a continuously cultivated legume grassland for fifteen, sixteen, eighteen, and twenty-two years, without any tillage. The experimental plots were located in the semi-arid region of the Chinese Loess Plateau, in a flat area without runoff contribution. All plant and soil samples, and measurements, were obtained in a few days to minimize the temporal variability. SWS increased at $50-150 \mathrm{~cm}$ soil depth when the proportion of legume functional group (LFG) decreased from $70 \%$ to $5 \%$, and this increment was ca. $20 \%$ at $50-100 \mathrm{~cm}$ soil layers. The Shannon-Wiener diversity index $(\mathrm{H})$, the species richness $(\mathrm{R})$, LFG, CP, and the non-capillary porosity (NCP) were significantly correlated with SWS $(\mathrm{P}<0.05)$. The infiltration capacity significantly improved when the proportion of LFG accounted for 5\%, which favored the recharge of the soil water reservoir with rainfall. Roots decay apparently improved the soil structure, and favored water infiltration, providing a suitable condition for latter vegetation growth. This study underlined the significant interaction that exists between the plant functional groups and the soil water processes during the artificial legume grassland succession. We proved that plant composition can change the surface hydrologic cycle, and the soil water exchange, in rainfed grassland.

Keywords: Legume grassland succession; Plant functional group; Roots decay; Infiltration rate; Soil water 


\section{Introduction}

Global warming leads to severe soil desiccation in many regions of the world (Morgan et al., 2010); and drought is an important factor driving the variation of plant community structure and function (Mariano et al., 2018; Xu et al., 2018). Moreover, grasslands are sensitive to drought owing to the limited water resources in the arid and semi-arid regions (Lijima et al., 2008). Alfalfa (Medicago sativa) is one of the widely planted leguminous forage, characterized by its high yield and drought resistance (Zhang and Shi, 2018). However, the combined effect of drought and long-term cultivation may trigger severe soil degradation in alfalfa grasslands (Ouyang et al., 2018). Degradation succession of legume grasslands driven drought is different from other forms of succession ( $\mathrm{Li}$ et al., 2010). The decay of roots would form stable soil macropores, which are beneficial for water flow (Angers and Caron, 1998; Devitt and Smith, 2002). Previous researches have indicated that conversion of forests into grasslands may increase the soil water content in the root zone (Yin et al., 2015). In a similar way, the tap roots decay of degraded legume grasslands may improve the soil water conditions in drylands. Thus, the study of the degradation processes of legume grasslands is particularly important to achieve a sustainable ecological restoration under the current changing environmental conditions (Newbold et al., 2015).

There is a broad agreement on the response of vegetation to drought, and on the effects of vegetation restoration on soil water content and dynamics (e.g. Brookshire and Weaver, 2015; Alamdarloo et al., 2018; Xu et al., 2018). These studies showed that soil water reduction would cause adverse effects on plant communities and soil properties (Wu et al., 2013). Drought results in a decrease of plant productivity and diversity that may further trigger severe land degradation (Mariano et al., 2018). Besides, unreasonable practices of vegetation restoration can aggravate soil desiccation in drylands (Jian et al., 2015). Further, drought negatively affect plant functional group composition, and soil properties, through changing the availability of nutrients and water (Aanderud et al., 2010). Grasslands had the ability to expand drought 
tolerant species, so that to resist dryness (Craine et al., 2013). Therefore, the degradation process of planted legume grasslands is not only a consequence of physiological changes, but also the result of adaptation to a changing environment. However, little is known about the effects of legume grasslands' degradation on soil water content (SWC) and its interactive mechanisms during the degradation processes. To understand the linkages between vegetation and SWC is essential for improving long-term ecosystem sustainability. Thus, new researches are necessary to quantify and analyze the response of SWC to the variation in the plant community structure, especially in the degraded planted legume grasslands in arid regions.

Plant functional group refers as the important bridge that connects the plant traits and ecosystem processes, and appears as a suitable concept for classifying differences in species functions (Eviner and Chapin, 2003). Plant community resists drought through changing the functional group composition (Stampfli et al., 2018). Additionally, the proportion of the above-ground biomass in different functional groups is primary to determine the plant responses to drought stress (Wu et al., 2014; Carlsson et al., 2017). In legume grasslands, drought causes the decrease of legume functional groups, and favors faster growing of more resource-acquisitive plants, such as the grasses (Stampfli et al., 2018). In contrary, variations in the plant community composition can generate feedback regulation on soil characteristics, such as SWC. Therefore, the study of the effects of legume grassland succession on the plant-soil interface is necessary to improve vegetation sustainability and to advance the understanding of soil water dynamics. To date, the processes of plant community succession and their effects on soil water condition in degraded planted legume grasslands have received little attention.

In this study, we evaluated the different stages of degradation of planted legume (alfalfa) grasslands in a semi-arid region of China. We divided the degradation succession into five stages according to the biomass proportion of each legume functional group. The plant community composition was divided into legumes, grasses and forbs (Carlsson et al., 2017). At each degradation stage, the proportion of biomass was calculated, 
and the soil properties were measured. We hypothesized that the soil water conditions improved due to the roots decay of the legume grassland along the degradation succession driven by drought. This research study sought to: (1) determine the soil water variation during the legume grassland degradation succession; and (2) analyze the potential mechanisms driving soil water variation. A better understanding of how vegetation succession drives soil moisture variation will help to improve the management strategies for vegetation restoration programs in drought regions.

\section{Materials and methods}

\subsection{Study site}

The experimental field is located in the Key Field Observation Station of the Ecological Environment of the Chinese Ministry of Agriculture $\left(36^{\circ} 01^{\prime} \mathrm{N}, 103^{\circ} 45^{\prime} \mathrm{E}\right)$ at $1,823 \mathrm{~m}$ a.s.l. in the central area of Gansu province. This area belongs to the semi-arid regions of the Loess Plateau, with a mean annual precipitation of $324.5 \mathrm{~mm}$, and a mean annual temperature of $9.3^{\circ} \mathrm{C}$. This study area does not have any water recharge resource but precipitation. The potential evaporation is approximately $1,450.0 \mathrm{~mm}$. The average gravimetric soil water content at field capacity is approximately $23 \%$. The main species used for planted grassland was alfalfa (Medicago sativa), while the most common natural grassland dominated species was Stipa capillata.

\subsection{Experimental design, plant and soil sampling}

Fig.1

We used the space-series variation of legume functional group to examine the effects of planted legume grassland degradation on the soil water content. We selected different degradation degrees of alfalfa grassland, which were continuously cultivated for fifteen, sixteen, eighteen, and twenty-two years, without any tillage. According to the above-ground biomass (AGB; $\mathrm{g} \mathrm{m}^{-2}$ ), and the proportion of legume functional 
group (LFG; \%) that changed with the different cultivated years, we divided the degradation process into five stages. The proportion thresholds of LFG were $85 \%, 70 \%, 45 \%, 25 \%$, and 5\%, namely LFG85, LFG70, LFG45, LFG25, and LFG5, respectively. The grasslands cultivated for twenty-two years presented different degradation degrees, and thus they were divided into LFG 25 and LFG5. Fig.1 illustrates the degraded succession process of planted alfalfa grassland selected in this study. The study site is flat and thus, runoff contribution was neglected.

Each treatment had more than three $1 \times 1$ m quadrats, and all samples were taken in mid-June in order to minimize the temporal variability of the measurements. AGB samples were collected according to the different functional groups (legumes, grass, and forbs). All samples were dried at $75^{\circ} \mathrm{C}$ for $48 \mathrm{~h}$ and weighed. The plant density and the total number of species $(S)$ for each quadrat were calculated. The below-ground biomass (BGB; $\mathrm{g} \mathrm{m}^{-2}$ ) was measured through digging soil sections, up to a maximum depth of about $120 \mathrm{~cm}$. Samples were taken from 0 to $100 \mathrm{~cm}$ depth with soil layers at 10 -cm intervals, in a sampling area of $25 \times 25$ $\mathrm{cm}$. Samples were washed through a $2 \mathrm{~mm}$ sieve, and picked out the impurities. Afterwards, roots were dried at $75^{\circ} \mathrm{C}$ for $48 \mathrm{~h}$ and weighed. Each treatment was done with three parallel samples in order to characterize the natural spatial variability of the soil properties.

The soil gravimetric water content $(\theta ; \%)$ was measured by using a $4-\mathrm{cm}$ diameter and 20 -cm height soil auger. Soil samples were taken from $0-200 \mathrm{~cm}$ at $10-\mathrm{cm}$ intervals. The soil bulk density $\left(B D ; \mathrm{g} \mathrm{cm}^{-3}\right)$ and the soil capillary water content $(W c ; \%)$ were measured in the field by using the cutting ring method $(5-\mathrm{cm}$ diameter and 5-cm height), and the sampling depth was $0-100 \mathrm{~cm}$ at $10-\mathrm{cm}$ intervals. All soil samples were measured at sampling conditions (wet weight) and soon after dried at $105^{\circ} \mathrm{C}$ for $48 \mathrm{~h}$. The soil organic matter was determined using the potassium chromate volumetric method (Walkley and Black, 1934). We used the automatic soil infiltrability measurement system to determine the soil infiltration rate (IR; $\mathrm{mm} \mathrm{h}^{-1}$ ) (Huang et al., 2017; Mao et al., 2016). Following the approach of Wu et al. (2016), the infiltration process (0-90 min) 
was divided into three temporal stages: (1) the fast infiltration stage (IRI, 0-15 min), (2) the stable change stage (IRII, 15-45 min), and (3) the remained stable stage (IRIII, 45-75 min). Moreover, the stable infiltration rate $\left(\mathrm{SIR} ; \mathrm{mm} \mathrm{h}^{-1}\right.$ ) was estimated as the mean value of IR at $75-90 \mathrm{~min}$, and the mean IR of the whole infiltration process was considered as the average infiltration rate (AIR).

\subsection{Laboratory measurements and analyses}

The soil water storage ( $S W S ; \mathrm{mm})$ was calculated as follows:

$$
S W S=h \times \theta \times B D \times 10^{-1}
$$

where $h$ is the soil depth (cm), $\theta$ is the soil gravimetric water content $(\%)$, and $B D$ is the soil bulk density $\left(\mathrm{g} \mathrm{cm}^{-3}\right)$. The soil total porosity $(T P ; \%)$, capillary porosity $(C P ; \%)$, and non-capillary porosity $(N C P ; \%)$ were calculated with the following equations:

$$
\begin{aligned}
& T P=\left(1-\frac{B D}{d s}\right) \times 100 \\
& C P=W c \times \frac{B D}{V} \times 100 \\
& N C P=T P-C P
\end{aligned}
$$

where $d s$ is the soil particle density $\left(2.65 \mathrm{~g} \mathrm{~cm}^{-3}\right), W c$ is the soil capillary water content $(\%)$, and $V$ is the volume of soil core $\left(\mathrm{cm}^{3}\right)$. The soil organic carbon storage (SOCS; $\mathrm{g} \mathrm{m}^{-2}$ ) was calculated using the following formula:

$$
S O C S=\sum_{i=1}^{n} B D_{i} \times S_{i} \times 0.58 \times h_{i} \times 10^{-1}
$$

where SOM is the soil organic matter content $\left(\mathrm{g} \mathrm{kg}^{-1}\right)$.

The species richness $(R)$, and the Shannon-Wiener diversity index $(H)$ were calculated using the following formulas:

$$
R=S
$$




$$
\begin{aligned}
& H=-\sum_{m=1}^{n} p_{m} \ln \left(p_{m}\right) \\
& p_{m}=\frac{n_{m}}{N}
\end{aligned}
$$

where $S$ is the number of species in the grassland (n), $p_{m}$ is the density of the $m$ species, $N$ is the total above-ground biomass $\left(\mathrm{g} \mathrm{m}^{-2}\right)$, and $n_{m}$ is the above-ground biomass of species $m\left(\mathrm{~g} \mathrm{~m}^{-2}\right)$.

\subsection{Statistical analyses}

The one-way analysis of variation $n$ (ANOVA), and the least significant difference (LSD) test were used to analyze the differences of the plant community traits and soil characteristics among the different degradation stages. The correlation between plant community traits, soil characteristics, and soil water storage were analyzed by using Pearson's correlation. All data analysis was carried out using SPSS 19.0 (IBM, USA) software.

The structural equation modeling (SEM) is one of the common multivariate data analysis methods which integrates the factor analysis and path analysis. Meanwhile, the direct, indirect, and total effects of independent variables on dependent variables are obtained through examining the relationships among variables, interference or errors contained in the model. In this study, SEM framework was used to explain the direct and indirect effects of LFG variables on SWC through H, BGB, CP, NCP, and SIR. Data were fitted to the model using the maximum-likelihood estimation method. The model adequacy was determined by using a Chi $^{2}$-test, Akaike Information Criterion (AIC) values, and Bayes Information Criterion (BIC). Non-significant $\mathrm{Chi}^{2}$-test $(\mathrm{P}>0.05)$, low AIC, and BIC indicated an adequate model fit. A non-significant $\mathrm{Chi}^{2}$-test $\left(\chi^{2}=15.6, d f=9, \mathrm{P}=0.076\right)$, $\mathrm{AIC}=53.60$ and $\mathrm{BIC}=-11.8$ was reported for the final model. R 3.2.2 2015 (Microsoft Corporation, USA) software was used for the SEM analysis. All charts were generated using R 3.2.2, except Figure 2 and Figure 4 that were created using SigmaPlot 14.0 (Systat Software Inc. San Jose, CA, USA) software. 


\section{Results}

\subsection{Characteristics of the plant functional groups}

Table 1, Fig. 2

With the degradation of the alfalfa grassland, the biomass proportion of LFG gradually decreased and GFG increased (Fig. 2). The biomass proportion of FFG was lower than LFG and GFG, and also decreased with the grassland degradation. The above-ground biomass decreased 30\% when the biomass proportion of LFG decreased from $85 \%$ to $5 \%$, while the below-ground biomass $(0-100 \mathrm{~cm})$ decreased $58.7 \%$ under this scenario. Species diversity $(4.8 \pm 1.8)$ and richness $(2.4 \pm 0.5)$ were lowest when the biomass of LFG accounts for $5 \%$ (Table 1).

\subsection{Changes in the soil physicochemical properties}

Table 2, Fig. 3

The highest soil water storage (SWS) was found in LFG85 $(32.24 \pm 2.11 \mathrm{~mm})$, and lower values were observed in LFG25 $(24.57 \pm 8.08 \mathrm{~mm})$, and LFG5 $(23.02 \pm 5.02 \mathrm{~mm})$ at top 0-50 $\mathrm{cm}$ soil depth (Fig. 3). The values of SWSs of LFG85 at the different soil depths were all significantly higher than those of SWSs of LFG5-70 (P<0.05), but there was no significant difference between LFG85 and LFG5 at the 50-100 cm soil layers $(\mathrm{P}>0.05)$. In general, SWS of LFG85 $(127.87 \pm 9.65 \mathrm{~mm})$ was approximately $44 \%$ higher than of SWS of LFG70, 38\% higher than of LFG25-45, and 30\% higher than of LFG5 (Table 2).

Fig. 4

The soil organic carbon storage (SOCS) in LFG5 at 0-100 cm was the lowest, and it was approximately 40\% and 50\% lower than those contents in LFG85 and LFG45-70, respectively (Fig. 4). SOCS mainly contributed in the $0-30 \mathrm{~cm}$ soil layers, totaling more than $40 \%$ of the total SOCS in the $0-100 \mathrm{~cm}$ soil depth. The SOCS in LFG25 and LFG5 were about 50\% and 30\% lower than in LFG45-70 and LFG85, respectively. 
The values of $\mathrm{BD}$ and $\mathrm{CP}$ of LFG45 were the lowest, and significantly lower than those values in LFG85 (P < 0.05); while TP and NCP of LFG45 were the highest and significantly higher than those values in LFG85 $(\mathrm{P}<0.05)$ in the top $0-10 \mathrm{~cm}$ soil depth (Table 2).

Fig. 5

The fast infiltration stage (IRI), the stable change infiltration stage (IRII), the remained stable infiltration stage (IRIII), the stable infiltration rate (SIR), and the average infiltration rate (AIR) reached their highest values when biomass proportion of LFG accounts for 5\% (Fig. 5). The differences of IRI between LFG25 to LFG85 were not significant (P > 0.05). IRII, IRIII, and SIR of LFG85 were significantly higher than LFG70\% $(\mathrm{P}<0.05)$.

\subsection{Correlations between the soil water storage and the plant functional groups and soil properties}

Fig. 6

The analysis of the correlation matrix showed that SWS was significantly and positively correlated with the soil $\mathrm{CP}$ at $0-20 \mathrm{~cm}$ soil depth (Fig. 6; P < 0.05), and significantly and negatively correlated with the soil NCP (Table 2; P < 0.05). The SWS of the 50-100 cm soil layers was significantly correlated with II, SIR, and AIR $(\mathrm{P}<0.05)$. The subsoil BD $(10-20 \mathrm{~cm})$ was significantly and negative correlated with the deeper SWS $(150-200 \mathrm{~cm})$, whereas soil TP $(10-20 \mathrm{~cm})$ was significantly and positive correlated with deeper SWS $(150-200 \mathrm{~cm})(\mathrm{P}<0.05)$. These results showed that the plant community had positive effects on SWS. Below the $100 \mathrm{~cm}$ soil depth, the SWS was significantly correlated with the biomass proportion of LFG and BGB. At $100-150 \mathrm{~cm}$ soil depth, the AGB was significantly correlated with SWS $(\mathrm{P}<0.05)$. Furthermore, $\mathrm{H}$ and R were significant correlated with SWS, except for the 50-100 $\mathrm{cm}$ soil depth layer. Generally, the relationship between SOCS and SWS was not significant. 


\subsection{Influence of the plant functional groups and soil properties on the soil water storage changes}

Fig. 7

The results of the structural equation model explained $90 \%$ of variation in the SWS $(0-200 \mathrm{~cm}$ soil depth) (Fig. 7). The structural equation model indicated that SWS was mainly explained by SIR and CP (0-10 cm soil depth). Moreover, the direct path coefficients of LFG on SWS was 0.25. The indirect path coefficients of LFG on SWS through $\mathrm{H}$ and CP were 0.31 and 0.44 , respectively. The BGB had a negative effect on SIR, and the indirect path coefficients on SWS through SIR was 0.28.

\section{Discussion}

It is known that long-term soil water deficit leads to a decrease of productivity and favors degradation of planted legume grasslands in arid and semi-arid regions (Brookshire and Weaver, 2015; Alamdarloo et al., 2018). Besides, the variation of community functional group triggers changes of diversity and richness; and plant diversity may have substantial effects on soil properties (Fischer et al., 2015). Wu et al. (2014) identified these changes as a response of plant communities to soil water content; and Angers and Caron (1998) suggested that the plant-induced variations of soil properties ultimately influenced the plant community by modifying the water cycle. In general, it is accepted that the interaction between plant community composition and SWS is the main feedback mechanism of succession (Liu et al., 2015). In this study, the variation of plant community composition had clear effects on SWS. During the planted legume grassland degradation to the grass dominated stage, SWS $(0-200 \mathrm{~cm}$ soil depth) gradually increased, especially at the 0-100 $\mathrm{cm}$ soil layers. This fact indicated that during the degradation process, SWS was restored when grass species dominated. Expect for the decreasing LFG that reduced its consumption on SWS, there were many factors involved. In the one hand, the LFG had positive correlation with the AGB and H of the plant community (Li et al., 2010). In the other hand, the LFG degradation also had critical effects on soil 
properties (Wu et al., 2017a). This study suggested that there were clear effects of LFG on SWS through soil by modifying the soil properties, for instance, the soil porosity and IR (Wu et al., 2016; Huang et al., 2017). Therefore, the variation of plant community composition was not only the response to SWS, but also an active factor influencing the SWS. In other words, the composition of plant functional group could influence the drought resistance and recovery capacity of grassland communities.

Our results showed that the biomass proportion of GFG increased with decreasing of LFG, while the variation of FFG was not significant. This result may be explained owing to the different water absorbing capacity of the roots of the different species. Compared to forbs tap-roots, grasses fibrous-roots could absorb more extensive soil water under dry conditions (Gordon et al., 1989), thus, favoring faster growth of GFG than the growth of FFG. Moreover, the productivity of legume grassland would be reduced due to long-term plantation (Huang et al., 2018). This research study showed that AGB changed in response to soil water changes, and it decreased $30 \%$ from the beginning of the succession until the grasses dominated stage. The BGB also decreased up to $60 \%$. Drought would result in the reduction of plant community productivity (Brookshire and Weaver, 2015). Nevertheless, SWC may increase when the dominated species of plant communities changed from legumes into grasses. Compared with legume grassland, the gramineae-dominated grassland consume less soil water (Cui et al., 2018). Besides these processes, the death of legume plants also caused the decay of roots. The root decay with LFG degradation was essential for improving the soil water infiltration capacity (Mitchell et al., 1995). Grasslands with higher infiltration capacity can improve the recharge of rainfall into the soil profile. In the present study, LFG had a significant and positive effects on BGB, and the IR increased with decreasing BGB. The decay of roots reduced the BGB, and formed stable soil macropores, which favor preferential flow (Mitchell et al., 1995). In addition to this process, Wu et al. (2017b) reported that the root channel diameter was higher in legume grassland than in the gramineous grassland. The root channel diameter also played a significant and positive effect on the 
initial infiltration rates (Wu et al., 2017b). In this study, infiltration capacity was higher when biomass proportion of LFG accounts for $85 \%$ and $5 \%$. This result suggested that the infiltration rates increased when the dominated species changed from legumes to gramineous in the degraded planted grassland. This evolution was beneficial for the improvement of the soil water content.

The effects of plant community and roots on the soil structure through nutrient input and embedded roots were important for researching the variation of soil water. However, in this study the relationship between SOCS and SWS was not significant. SOCS gradually decreased with the degradation succession (Li et al., 2014). We found that the proportion of LFG had significant and positive effects on the soil capillary porosity $(\mathrm{CP})$, and negative effects on the non-capillary porosity (NCP). This means that during the degradation process of LFG, the NCP increased, and conversely, the CP decreased. The combined effect of the presence of fibrous roots and the decay of tap roots caused an increase in NCP (Jiang et al., 2018). The CP had significant and positive effects on SWS, but negative effects on SIR. This result can be explained because the $\mathrm{CP}$, with higher water-holding capacity, could maintain more soil water, being unfavorable for the water movement along the soil profile (Huang et al., 2017; Pan et al., 2018). At the same time, the NCP showed a negative effect on SIR, and was negatively correlated with SWS. These observations were not consistency with previous studies, which suggested that NCP could promote water infiltration and positive correlated with SWS (Zhang et al., 2016; Pan et al., 2018). This fact may be explained by the long-term drought conditions in our study area that made the advantage of soil NCP in increasing SWS not obvious. Overall, the variation of SWS was mainly explained by the indirect effects of LFG through roots. However, in this study, we did not divide the below-ground biomass into legume roots or grass roots and living roots or dead roots, and this research need to be achieved in further studies to quantify the effects of legume death roots on soil water. 


\section{Conclusions}

The increasing soil drought conditions resulted in a degradation succession of the artificial legume grassland, which gradually formulated grasses with forbs functional groups-dominated grassland community that appeared to be favored by drought environments. Our results showed that the increasing functional groups of grasses with forbs reduced the soil water consumption, and presented lower water consumption and stronger adaptability to arid habitats. Meanwhile, soil infiltration capacity increased through the death and decay of the roots of the legume functional group. The soil water storage also increased because of the increasing soil porosity and roots channel characteristics during this degradation succession process, especially at the 50-150 cm soil layers. In general, an important interaction between the plant functional groups and the soil water processes was observed during the artificial legume grassland succession. We concluded that plant functional group composition can change the surface hydrologic cycle and thus the soil water exchange in grassland communities.

\section{Acknowledgments}

We thank the editors and anonymous reviewers for their constructive comments and suggestions on this work, and thank Dr. João Carlos Marques for his suggestions on this manuscript. This research was funded by the National Natural Science Foundation of China (NSFC 41722107 and 41525003), the Light of West China Program of Chinese Academy of Sciences (XAB2015A04 and XAB2018B09), and the Youth Talent Plan Foundation of Northwest A\&F University (2452018025), and the Agricultural Science and Technology Innovation Program of Chinese Academy of Agricultural Sciences (CAAS-ASTIP-2016-LIHPS-08).

\section{References}

Aanderud, Z.T., Richards, J.H., Svejcar, T., James, J.J., 2010. A shift in seasonal rainfall reduces soil organic carbon storage in a cold desert. Ecosystems 13, 673-682. https://doi.org/10.1007/s10021-010-9346-1

Alamdarloo, E.H., Manesh, M.B., Khosravi, H., 2018. Probability assessment of vegetation vulnerability to drought based on remote sensing data. Environ. Monit. Assess. 190, 702. https://doi.org/10.1007/s10661-018-7089-1 
Angers, D.A., Caron, J., 1998. Plant-induced changes in soil structure: Processes and feedbacks. Biogeochemistry 42, 55-72. https://doi.org/10.1023/a:1005944025343

Brookshire, E.N.J., Weaver, T., 2015. Long-term decline in grassland productivity driven by increasing dryness. Nat. Commun. 6, 7148. https://doi.org/10.1038/ncomms8148

Carlsson, M., Merten, M., Kayser, M., Isselstein, J., Wrage-Monnig, N., 2017. Drought stress resistance and resilience of permanent grasslands are shaped by functional group composition and $\mathrm{N}$ fertilization. Agr. Ecosyst. Environ. 236, 52-60. https://doi.org/10.1016/j.agee.2016.11.009

Craine, J.M., Ocheltree, T.W., Nippert, J.B., Towne, E.G., Skibbe, A.M., Kembel, S.W., Fargione, J.E., 2013. Global diversity of drought tolerance and grassland climate-change resilience. Nat. Clim. Change 3, 63-67. https://doi.org/10.1038/nclimate1634

Cui, Z., Liu, Y., Jia, C., Huang, Z., He, H.H., Han, F.P., Shen, W.B., Wu, G.L., 2018. Soil water storage compensation potential of herbaceous energy crops in semi-arid region. Field Crop Res. 223, 41-47. https://doi.org/10.1016/j.fcr.2018.03.026

Devitt, D.A., Smith, S.D., 2002. Root channel macropores enhance downward movement of water in a Mojave Desert ecosystem. J. Arid Environ. 50, 99-108. https://doi.org/10.1006/jare.2001.0853

Eviner, V.T., Chapin, F.S., 2003. Functional matrix: A conceptual framework for predicting multiple plant effects on $\begin{array}{llll}\text { ecosystem } \quad \text { processes. } & \text { Annu. Rev. Ecol. Evol. Systemat. } & \text { 34, }\end{array}$ https://doi.org/10.1146/annurev.ecolsys.34.011802.132342

Fischer, C., Tischer, J., Roscher, C., Eisenhauer, N., Ravenek, J., Gleixner, G., Attinger, S., Jensen, B., de Kroon, H., Mommer, L., Scheu, S., Hildebrandt, A., 2015. Plant species diversity affects infiltration capacity in an experimental grassland through changes in soil properties. Plant Soil 397, 1-16. https://doi.org/10.1007/s11104-014-2373-5

Gordon, D.R., Menke, J.M., Rice, K.J., Rice, K.J., 1989. Competition for water between annual plants and blue oak (Quercus douglasii) seedlings. Oecologia 79, 533-541. https://doi.org/10.1007/BF00378672

Huang, Z., Tian, F.P., Wu, G.L., Liu, Y., Dang, Z.Q., 2017. Legume grasslands promote precipitation infiltration better than Gramineous grasslands in arid regions. Land Degrad. Dev. 28, 309-316. https://doi.org/10.1002/ldr.2635

Huang, Z., Liu, Y., Cui, Z., He, H.H., Liu, B.R., Wu, G.L., 2018. Soil water storage deficit of alfalfa (Medicago sativa) grasslands along ages in arid area (China). Field Crop Res. 221, 1-6. https://doi.org/10.1016/j.fcr.2018.02.013

Jian, S.Q., Zhao, C.Y., Fang, S.M., Yu, K., 2015. Effects of different vegetation restoration on soil water storage and water balance in the Chinese Loess Plateau. Agr. Forest Meteorol. 206, 85-96. https://doi.org/10.1016/j.agrformet.2015.03.009 
Jiang, X.J., Liu, W.J., Chen, C.F., Liu, J.Q., Yuan, Z.Q., Jin, B.C., Yu, X.Y., 2018. Effects of three morphometric features of roots on soil water flow behavior in three sites in China. Geoderma 320, 161-171. https://doi.org/10.1016/j.geoderma.2018.01.035

Li, W.J., Li, J.H., Lu, J.F., Zhang, R.Y., Wang, G., 2010. Legume-grass species influence plant productivity and soil nitrogen during grassland succession in the eastern Tibet Plateau. Appl. Soil Ecol. 44, $164-169$. https://doi.org/10.1016/j.apsoil.2009.12.001

Li, Y.Y., Dong, S.K., Wen, L., Wang, X.X., Wu, Y., 2014. Soil carbon and nitrogen pools and their relationship to plant and soil dynamics of degraded and artificially restored grasslands of the Qinghai-Tibetan Plateau. Geoderma 213, 178-184. https://doi.org/10.1016/j.geoderma.2013.08.022

Iijima, Y., Kawaragi, T., Ito T., Akshalov, K., Tsunekawa, A., Shinoda, M., 2010. Response of plant growth to surface water balance during a summer dry period in the Kazakhstan steppe. Hydrol. Process. 22, $2974-2981$. https://doi.org/10.1002/hyp.6870

Liu, B., Zhao, W.Z., Liu, Z.L., Yang, Y.T., Luo, W.C., Zhou, H., Zhang, Y.Y., 2015. Changes in species diversity, aboveground biomass, and vegetation cover along an afforestation successional gradient in a semiarid desert steppe of China. Ecol. Eng. 81, 301-311. https://doi.org/10.1016/j.ecoleng.2015.04.014

Mao, L.L., Li, Y.Z., Hao, W.P., Mei, X.R., Bralts, V.F., Li, H.R., Guo, R., Lei, T.W., 2016. An approximate point source method for soil infiltration process measurement. Geoderma 264, 10-16. https://doi.org/10.1016/j.geoderma.2015.09.011

Mariano, D.A., dos Santos, C.A.C., Wardlow, B.D., Anderson, M.C., Schiltmeyer, A.V., Tadesse, T., Svoboda, M.D., 2018. Use of remote sensing indicators to assess effects of drought and human-induced land degradation on ecosystem health in Northeastern Brazil. Remote Sens. Environ. 213, 129-143. https://doi.org/10.1016/j.rse.2018.04.048

Mitchell, A.R., Ellsworth, T.R,, Meek, B.D., 1995. Effect of root systems on preferential flow in swelling soil. Commun. Soil Sci. Plant Anal. 26, 2655-2666. https://doi.org/10.1080/00103629509369475

Morgan, J.A., LeCain, D.R., Pendall, E., Blumenthal, D.M., Kimball, B.A., Carrillo, Y., Williams, D.G., Heisler-White, J., Dijkstra, F.A., West, M., 2011. C $_{4}$ grasses prosper as carbon dioxide eliminates desiccation in warmed semi-arid grassland. Nature 476, 202-206. https://doi.org/10.1038/nature10274

Newbold, T., Hudson, L.N., Hill, S.L.L., Contu, S., Lysenko, I., Senior, R.A., Borger, L., Bennett, D.J., Choimes, A., Collen, B., Day, J., De Palma, A., Diaz, S., Echeverria-Londono, S., Edgar, M.J., Feldman, A., Garon, M., Harrison, M.L.K., Alhusseini, T., Ingram, D.J., Itescu, Y., Kattge, J., Kemp, V., Kirkpatrick, L., Kleyer, M., Correia, D.L.P., Martin, C.D., Meiri, S., Novosolov, M., Pan, Y., Phillips, H.R.P., Purves, D.W., Robinson, A., Simpson, J., Tuck, 
S.L., Weiher, E., White, H.J., Ewers, R.M., Mace, G.M., Scharlemann, J.P.W., Purvis, A., 2015. Global effects of land use on local terrestrial biodiversity. Nature 520, 45-50. https://doi.org/10.1038/nature14324

Ouyang, W., Wu, Y., Hao, Z., Zhang, Q., Bu, Q., Gao, X., 2018. Combined impacts of land use and soil property changes on soil erosion in a mollisol area under long-term agricultural development. Sci.Total Environ. 613-614, 798-809. https://doi.org/10.1016/j.scitotenv.2017.09.173

Pan, T., Hou, S., Wu, S.H., Liu, Y.J., Liu, Y.H., Zou, X.T., Herzberger, A., Liu, J.G., 2017. Variation of soil hydraulic properties with alpine grassland degradation in the eastern Tibetan Plateau. Hydrol. Earth Syst. Sci. 21, $2249-2261$. https://doi.org/10.5194/hess-21-2249-2017

Stampfli, A., Bloor, J.M.G., Fischer, M., Zeiter, M., 2018. High land-use intensity exacerbates shifts in grassland vegetation composition after severe experimental drought. Global Change Biol. 24, 2021-2034. https://doi.org/10.1111/gcb.14046

Walkley, A.J., Black, I.A., 1934. An examination of the degtjareff method for determining soil organic matter, and a proposed modification of the chromic acid titration method. Soil Sci. 37, 29-38. https://doi.org/10.1097/00010694-193401000-00003

Wu, G.L., Liu, Y., Tian, F.P., Shi, Z.H., 2017a. Legumes functional group promotes soil organic carbon and nitrogen storage by increasing plant diversity. Land Degrad. Dev. 28, 1336-1344. https://doi.org/10.1002/ldr.2570

Wu, G.L., Liu, Y., Yang, Z., Cui, Z., Deng, L., Chang, X.F., Shi, Z.H., 2017b. Root channels to indicate the increase in soil matrix water infiltration capacity of arid reclaimed mine soils. J. Hydrol. 546, $133-139$. https://doi.org/10.1016/j.jhydrol.2016.12.047

Wu, G.L., Zhang, Z.N., Wang, D., Shi, Z.H., Zhu, Y.J., 2014. Interactions of soil water content heterogeneity and species diversity patterns in semi-arid steppes on the Loess Plateau of China. J. Hydrol. 519, 1362-1367. https://doi.org/10.1016/j.jhydrol.2014.09.012

Wu, G.L., Yang, Z., Cui, Z., Liu, Y., Fang, N.F., Shi, Z.H., 2016. Mixed artificial grasslands with more roots improved mine soil infiltration capacity. J. Hydrol. 535, 54-60. https://doi.org/10.1016/j.jhydrol.2016.01.059

Wu, G.L., Ren, G.H., Wang, D., Shi, Z.H., Warrington, D., 2013. Above- and below-ground response to soil water change in an alpine wetland ecosystem on the Qinghai-Tibetan Plateau, China. J. Hydrol. 476, $120-127$. https://doi.org/10.1016/j.jhydrol.2012.10.031

Xu, H.J., Wang, X.P., Zhao, C.Y., Yang, X.M., 2018. Diverse responses of vegetation growth to meteorological drought across climate zones and land biomes in northern China from 1981 to 2014. Agr. Forest Meteorol. 262, 1-13. https://doi.org/10.1016/j.agrformet.2018.06.027

Yin, J.F., Zheng, Y.F., Zhan, X.W., Hain, C.R., Zhai, Q.F., Duan, C.C., Wu, R.J., Liu, J.C., Fang, L., 2015. An 
assessment of impacts of land-cover changes on root-zone soil moisture. Int. J. Remote Sens. 36, 6116-6134. https://doi.org/10.1080/01431161.2015.1111539

Zhang, C.M., Shi, S.L., 2018. Physiological and proteomic responses of contrasting alfalfa (Medicago sativa L.) varieties to PEG-induced osmotic stress. Front. Plant Sci. 9, 242. https://doi.org/10.3389/fpls.2018.00242

Zhang, Y.W., Deng, L., Yan, W.M., Shangguan, Z.P., 2016. Interaction of soil water storage dynamics and long-term natural vegetation succession on the Loess Plateau, China. Catena 137, 52-60. https://doi.org/10.1016/j.catena.2015.08.016 
Table 1. Mean ( \pm standard deviation) values of the surface coverage, Shannon-Wiener diversity index $(H)$, species richness $(\mathrm{R})$, and the dominant species of the five succession stages with different proportion of the legume functional group (PLFG).

\begin{tabular}{|c|c|c|c|c|c|}
\hline $\begin{array}{c}\text { Succession } \\
\text { stage }\end{array}$ & $\begin{array}{l}\text { PLFG } \\
(\%)\end{array}$ & $\begin{array}{c}\text { Coverage } \\
(\%)\end{array}$ & $\mathrm{H}$ & $\mathrm{R}$ & Dominant species \\
\hline 1 & LFG85 & 90 & $19.8 \pm 2.1 \mathrm{a}$ & $5.7 \pm 0.6 \mathrm{a}$ & Medicago sativa \\
\hline 2 & LFG70 & 80 & $8.7 \pm 0.5 \mathrm{bc}$ & $3.8 \pm 0.5 \mathrm{bc}$ & Medicago sativa \\
\hline 3 & LFG45 & 75 & $12.1 \pm 3.4 \mathrm{~b}$ & $4.5 \pm 0.6 \mathrm{ab}$ & Medicago sativa, Stipa capillata \\
\hline 4 & LFG25 & 80 & $11.2 \pm 6.4 \mathrm{~b}$ & $4.8 \pm 1.9 \mathrm{ab}$ & Stipa capillata \\
\hline 5 & LFG5 & 85 & $4.8 \pm 1.8 \mathrm{c}$ & $2.4 \pm 0.5 \mathrm{c}$ & Stipa capillata \\
\hline
\end{tabular}

Within column, values followed by different letters are significantly different between them at $\mathrm{P}<0.05$ (using Fisher's least significant difference procedure).

Table 2. Mean \pm standard deviation values of soil water storage ( $S W S, 0-200 \mathrm{~cm}$ ), bulk density (BD), total porosity (TP), capillary porosity (CP), and non-capillary porosity (NCP) in the different succession stages at $0-10 \mathrm{~cm}$ soil depth.

\begin{tabular}{cccccc}
\hline $\begin{array}{c}\text { Succession } \\
\text { stage }\end{array}$ & SWS $(\mathrm{mm})$ & $\mathrm{BD}\left(\mathrm{g} \mathrm{cm}^{-3}\right)$ & $\mathrm{TP}(\%)$ & $\mathrm{CP}(\%)$ & NCP $(\%)$ \\
\hline 1 & $127.87 \pm 9.65 \mathrm{a}$ & $1.35 \pm 0.03 \mathrm{a}$ & $49.01 \pm 1.17 \mathrm{~b}$ & $26.14 \pm 0.60 \mathrm{a}$ & $22.87 \pm 1.77 \mathrm{~b}$ \\
2 & $89.05 \pm 8.09 \mathrm{~b}$ & $1.33 \pm 0.03 \mathrm{ab}$ & $49.70 \pm 0.97 \mathrm{ab}$ & $25.79 \pm 0.50 \mathrm{ab}$ & $23.91 \pm 1.46 \mathrm{ab}$ \\
3 & $92.40 \pm 9.94 \mathrm{~b}$ & $1.31 \pm 0.01 \mathrm{~b}$ & $50.66 \pm 0.27 \mathrm{a}$ & $25.29 \pm 0.14 \mathrm{~b}$ & $25.36 \pm 0.41 \mathrm{a}$ \\
4 & $93.31 \pm 14.21 \mathrm{~b}$ & $1.32 \pm 0.03 \mathrm{ab}$ & $50.1 \pm 0.99 \mathrm{ab}$ & $25.58 \pm 0.51 \mathrm{ab}$ & $24.52 \pm 1.50 \mathrm{ab}$ \\
5 & $96.79 \pm 14.86 \mathrm{~b}$ & $1.32 \pm 0.02 \mathrm{ab}$ & $50.21 \pm 0.57 \mathrm{ab}$ & $25.52 \pm 0.29 \mathrm{ab}$ & $24.69 \pm 0.86 \mathrm{ab}$ \\
\hline
\end{tabular}

Within column, values followed by different letters are significantly different between them at $\mathrm{P}<0.05$ (using Fisher's least significant difference procedure). 
Fig. 1. Illustration of the planted grassland degradation succession process showing the proportion of legume functional group (LFG), the above-ground biomass decrease (from $85 \%$ to $5 \%$ ), and the soil water content (SWC) variation at 0-200 $\mathrm{cm}$ soil depth. The legume roots are drawn in blue and the grass roots in black.

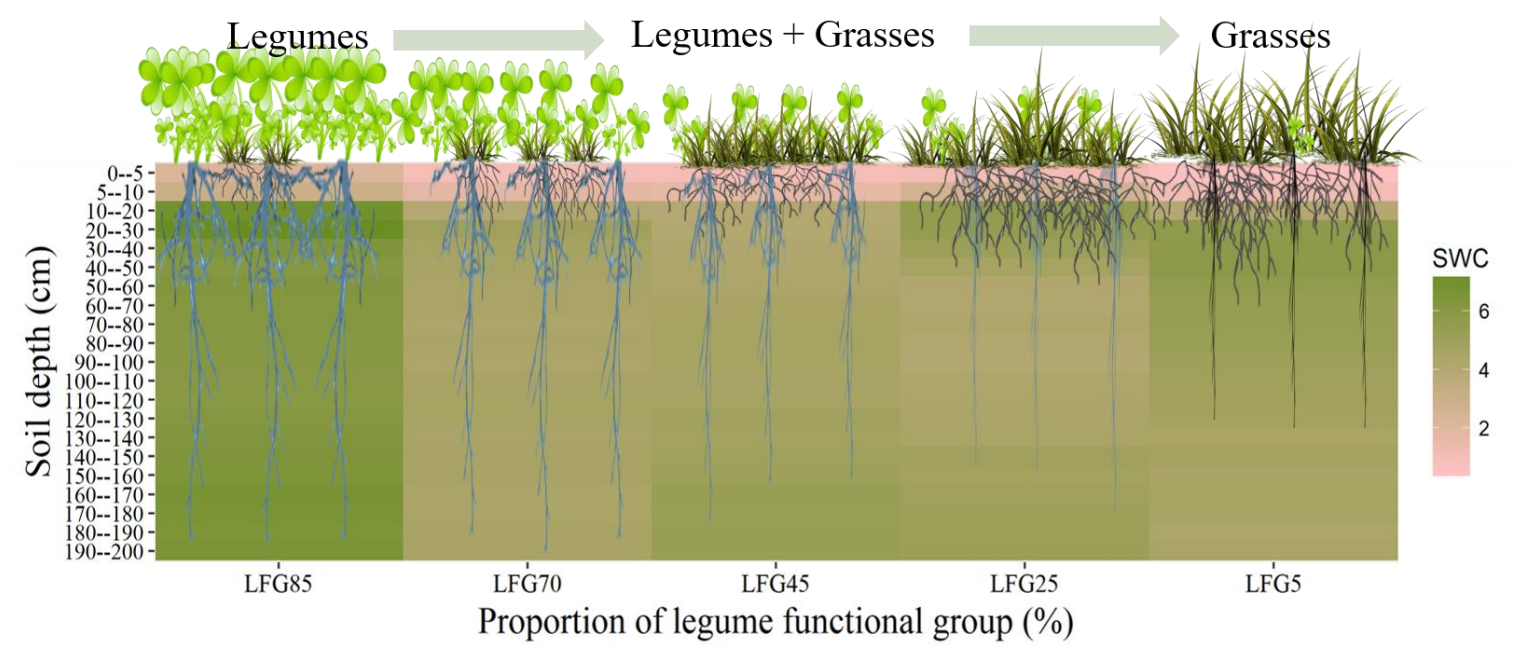


Fig. 2. Changes of the above-ground biomass (AGB) of the legume functional group (LFG), the grass functional group (GFG), and the forbs functional group (FFG) along the planted legume grassland degraded succession. The below-ground biomass (BGB) variation at $0-30 \mathrm{~cm}$, and $30-100 \mathrm{~cm}$ soil depth is also included. Different letters in different succession stages imply significant differences $(\mathrm{P}<0.05)$.

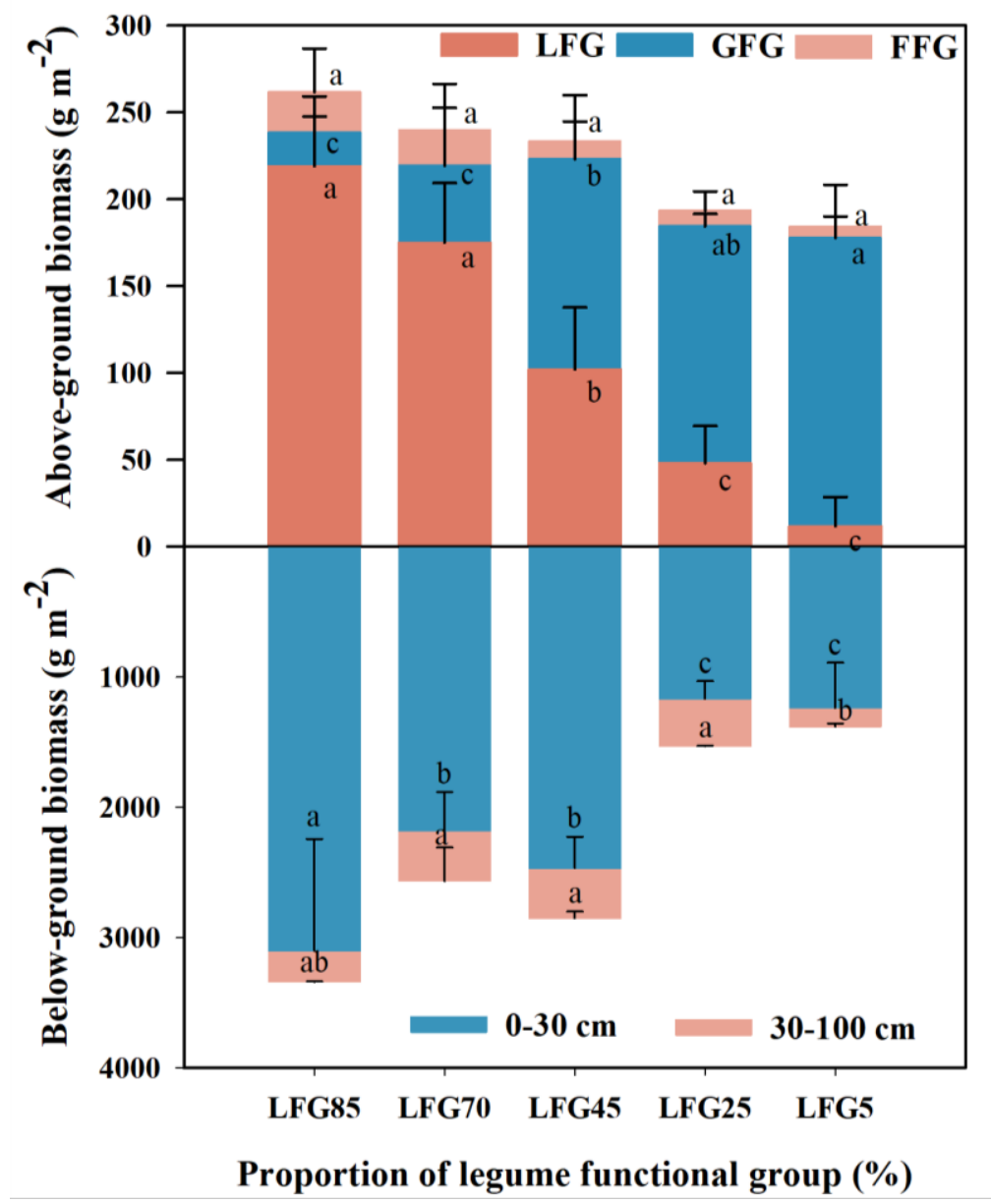


Fig. 3. Soil water storage (SWS) variation of $0-50 \mathrm{~cm}, 50-100 \mathrm{~cm}, 100-150 \mathrm{~cm}$, and 150-200 cm soil depth with decreasing the above-ground biomass of the legume functional group in the planted legume grassland. *: Difference is significant at the 0.05 level.

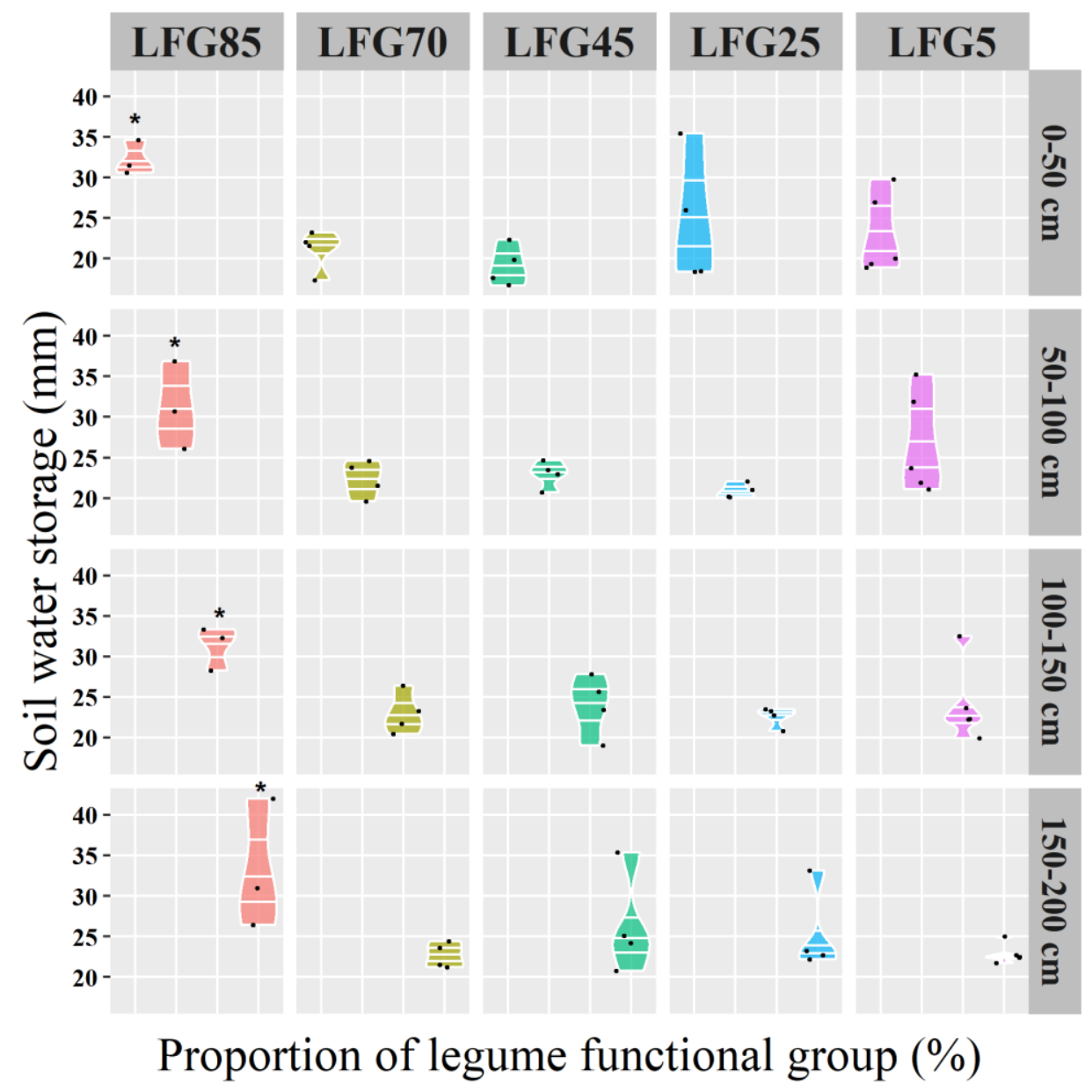


Fig. 4. Soil organic carbon storage (SOCS) variation at $0-30 \mathrm{~cm}$, and $30-100 \mathrm{~cm}$ soil depth along the decreasing above-ground biomass proportion of the legume functional group in the planted legume grassland. Different letters in different proportions of the legume functional group imply that the difference was significant at the 0.05 level.

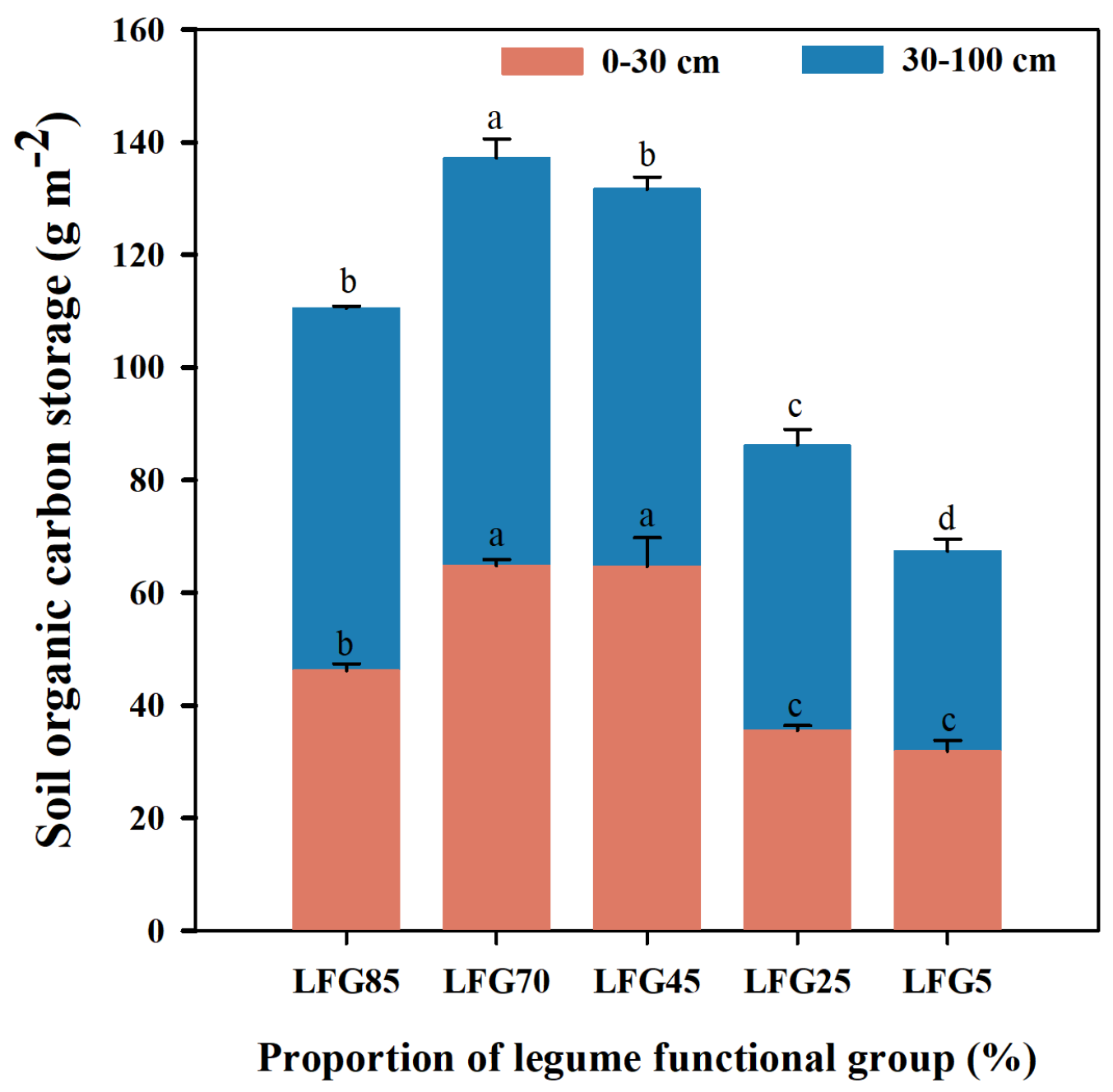


Fig. 5. Variation of the average soil water infiltration rates during stages I (0-15 min), II (15-45 min), III (45-75 $\mathrm{min}$ ), steady infiltration rate (SIR), and 0-90 min average infiltration rate (AIR) along the decreasing proportion of the legume functional group in the planted legume grassland. Different letters in the different proportions of legume functional group imply that the difference was significant at the 0.05 level.

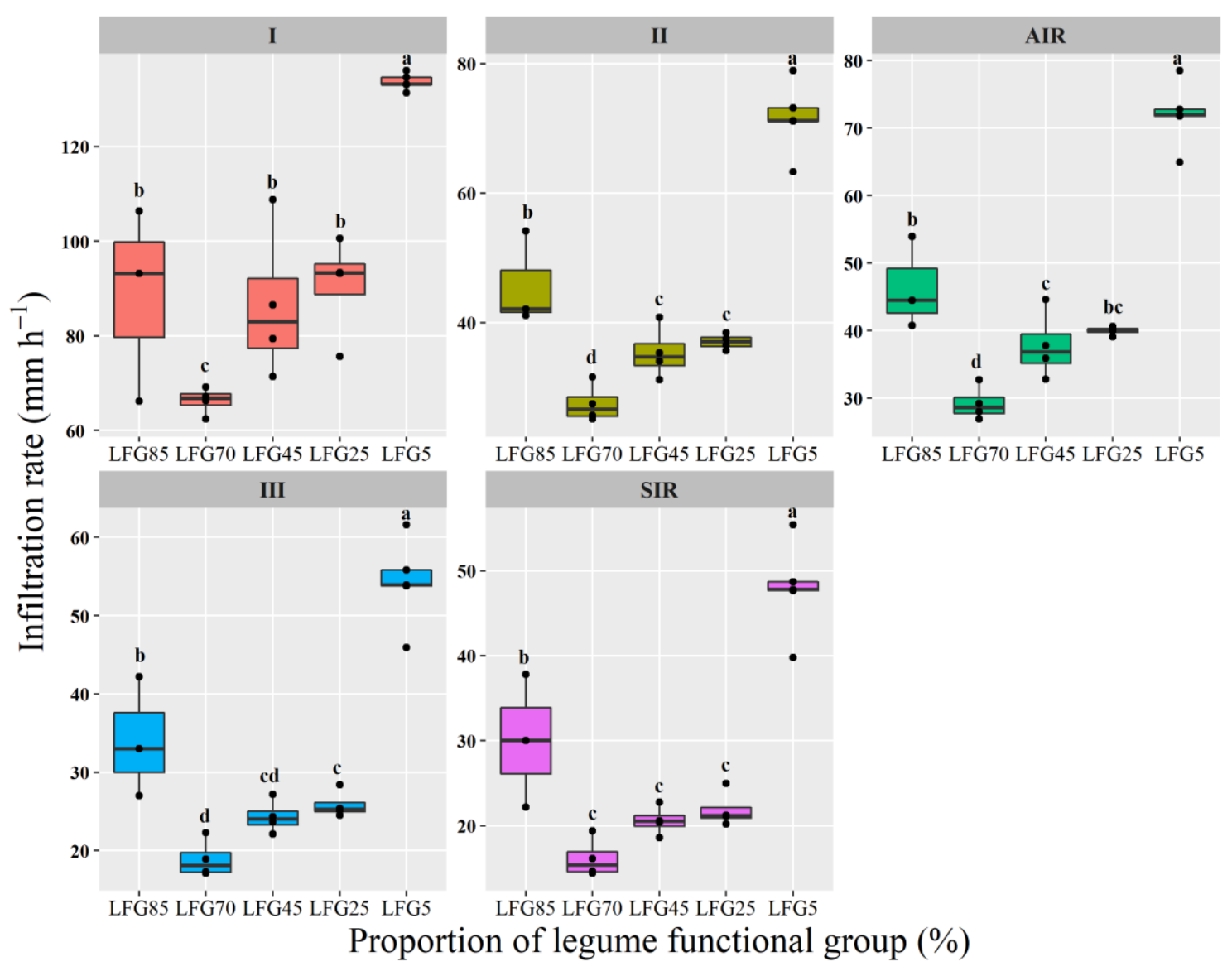


Fig. 6. Pearson correlations' analysis for the plant community traits and soil characteristics. SWS0-50, 50-100, 100-150, 150-200 and 0-200 are the soil water storage at 0-50 cm, 50-100 cm, 100-150 cm, 150-200 $\mathrm{cm}$, and 0-200 $\mathrm{cm}$ soil depth. AGB is the above-ground biomass. BGB0-100 is the below-ground biomass at 0-100 cm. $\mathrm{H}$ is the Shannon-Wiener diversity index. $\mathrm{R}$ is the species richness. LFG is the proportion of legume functional group. SIR is the steady infiltration rate. TP10, CP10 and NCP10 are the total porosity, capillary porosity, and non-capillary porosity at $0-10 \mathrm{~cm}$ soil depth. *: Correlation is significant at the 0.05 level; **: Correlation is significant at the 0.01 level; ***: Correlation is significant at the 0.001 level.

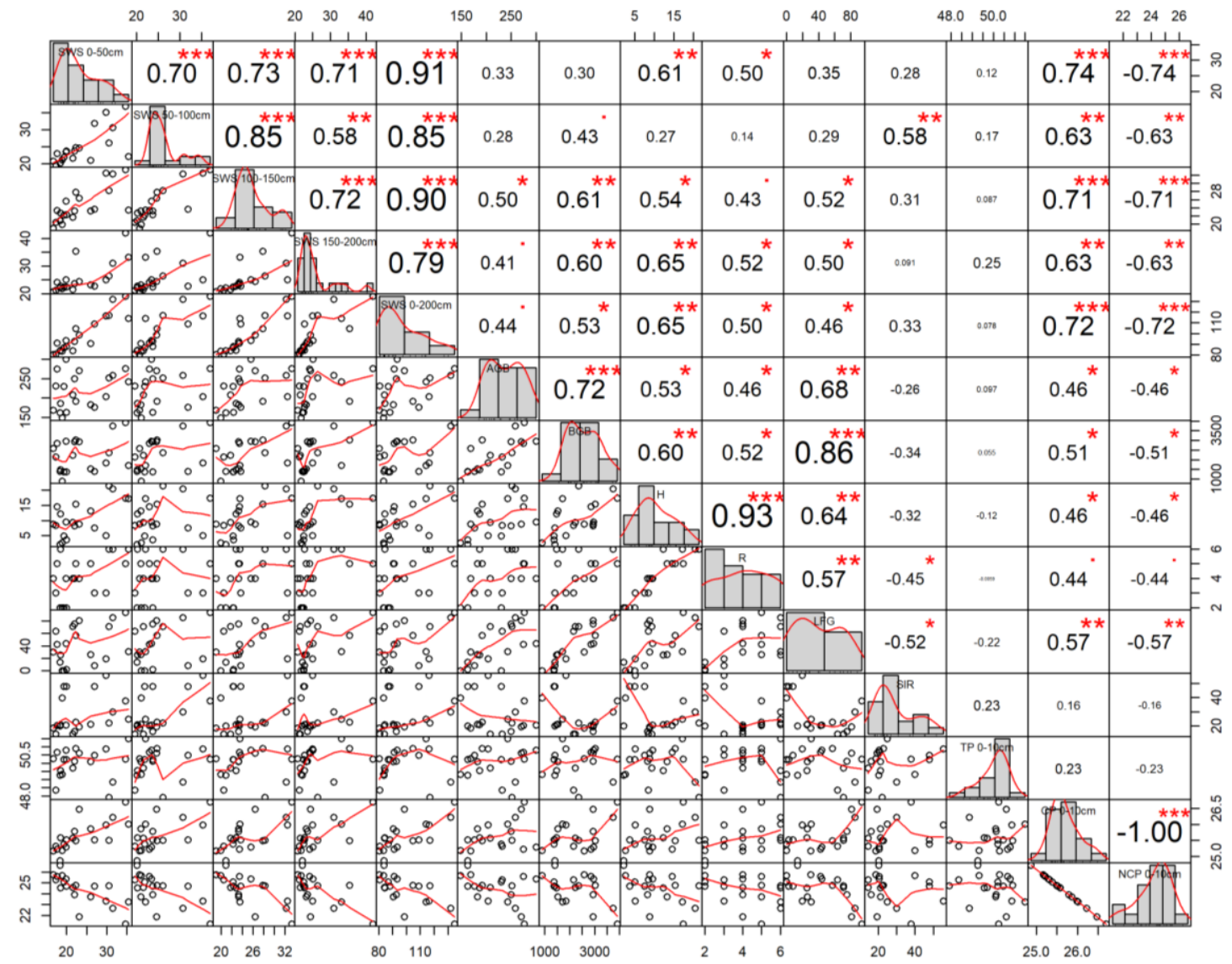


Fig. 7. Proposed path analysis representing the hypothesized casual relationships between the proportion of legume functional group (LFG), the Shannon-Wiener diversity index (H), the capillary (CP) and non-capillary porosity ( $\mathrm{NCP}$, in $0-10 \mathrm{~cm}$ depth), the below-ground biomass (BGB, in $0-10 \mathrm{~cm}$ depth), the steady infiltration rate (SIR), and the soil water storage (SWS, in 0-200 $\mathrm{cm}$ depth). The thickness of the arrow line imply the strength of the causal influence. Bold arrows indicate the significant standardized path coefficients $(\mathrm{P}<0.05)$. The stars indicate the significance level, $(* \mathrm{P}<0.05, * * \mathrm{P}<0.01, * * * \mathrm{P}<0.001)$.

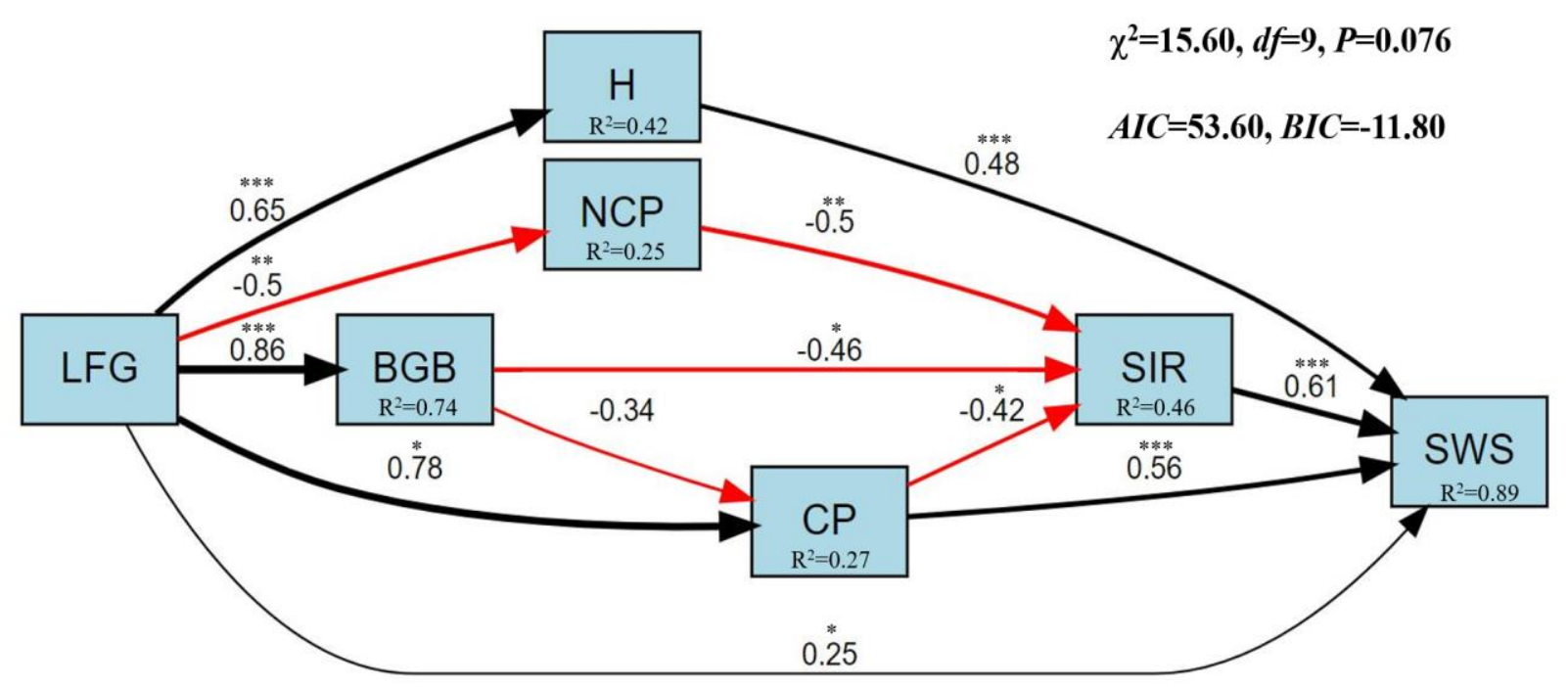

